\title{
Mobile Heterotopia: Movement, Circulation and the Function of the University
}

\author{
BRADLEY RINK \\ Department of Geography, Environmental Studies \& Tourism, \\ University of the Western Cape
}

This paper explores the function of the university through the lens of mobility as seen from a South African perspective. Understanding the role of the university as one that requires the movement and circulation of academic bodies in the form of students and staff, and bodies of academic knowledge in the form of teaching, research and academic content, I use a theoretical framework from the interdisciplinary field of mobilities in order to understand the role of movement in the university and to highlight what is ruptured and catalysed by frictions enacted through power geometry, austerity and disruption. Sighted from the perspective of the University of the Western Cape in South Africa, this paper poses a series of provocations that reveal the obligations of presence that comprise the production and transfer of knowledge in the twenty-first-century university. I discuss how disruption and austerity, amongst other embedded mobility limitations, impact on the multiple/intersecting universes of the university; how the austere and disrupted university influences our engagement at various scales from local to global; and, finally, how disruption and austerity act to fix academic bodies in place even as they may allow virtual mobility to replace the face-to-face engagement that is the hallmark of the academic project. This paper demonstrates the critical role of mobility in the institution of the university and concludes that the university is a form of Foucauldian heterotopia mobilising diverse academic bodies and bodies of knowledge.

\section{Keywords:}

mobility, austerity, disruption, network capital, heterotopia

As a mobilities scholar I am keenly aware of the role of movement and stasis in social life. However, at the end of a recent visit to the USA I began to think more closely about the role of mobility in academia, and the impact that disruption and austerity may have on the stated purpose of the university as articulated through mission statements of a small sample of institutions in South Africa as well as the resulting function of such universities in Africa and beyond. My whirlwind visit to the USA was funded through a variety of sources cobbled together. While the multitude of sources and the holding of a US passport made the trip possible, the fast-paced, hastily constructed visit also required me to attend to myriad projects across a wide geographical and theoretical space. The experience on which I reflected at the moment inspired me to think about the extraordinary and yet mundane nature of my mobility 
as a scholar within a South African university. That led to introspection over the ways in which mobility plays a critical role in the knowledge institution of the university and the meaning of friction in the form of disruption and austerity in my work as a teacher and scholar.

With this in mind, the principle contributions of this paper are twofold: first, I intend to situate the purpose (as qualified above) and resulting function of the knowledge institution of the university within the interdisciplinary field of mobilities. In doing so, I will trace the role of mobilities from the earliest history of the university to the present-day frenetically mobile world that may be understood through Mimi Sheller and John Urry's 'new mobilities paradigm.' ${ }^{1}$ While Sheller and Urry's understanding of mobilities highlights the movement and circulation of people, nonhuman animals, objects, capital and information, I use the theoretical framework of mobilities with reference to the movement and circulation of academic bodies in the corporeal sense, and in the movement and circulation of bodies of knowledge as evidenced through objects and information. The theoretical lens of mobility relates to my second contribution, which is to discuss the disciplining actions and impacts of university disruption and austerity, and the obligations of presence within the university environment. I take inspiration from Tom Storme and colleagues in deploying the terms 'obligation' (from the Latin obligare; ob- 'toward' and ligare 'to bind') ${ }^{2}$ and 'presence' in their corporeal and material meanings to highlight the commitment of teachers, students and scholars in the pursuit and sharing of knowledge. ${ }^{3}$ At the same time, I speak back to Storme et al. from the perspective of the global South, where power geometry acts to inhibit the career-expanding mobility practices that they discuss. In doing so I use a disciplinary framework from human geography, including scale, fixity and space, to understand the function of the university and the ways in which the austere and disrupted university ruptures or influences our engagement at various scales from local to global.

At the same time, I pose a series of provocations for further discussion with respect to the disrupted and austere university and its impacts on mobility, specifically with regard to the movement and circulation of academic bodies and bodies of academic knowledge as seen from a South African university perspective. My provocations concern the impacts of mobility frictions, including but not limited to austerity, on the multiple/intersecting 'universe(s)' of the university and the obligations of presence that we necessarily enact or forgo in the midst of disrupted or fractioned flows of knowledge. In other words, how do disruption and austerity act to mobilise or fix academic bodies in place even as they may both demand and enable new forms of mobility (such as virtual mobility) to be practised? The answers to these questions come to bear on the function of the university that results from a variety of relationships at multiple scales, and by extension the accumulation of network capital and

\footnotetext{
M. Sheller and J. Urry, 'The New Mobilities Paradigm', Environment and Planning D: Society and Space, 38 (2006), 207-226.

T. Storme, J.R. Faulconbridge, J.V. Beaverstock, B. Derudder and F. Witlox, 'Mobility and Professional Networks in Academia: An Exploration of the Obligations of Presence', Mobilities, (2016), 1-20. doi: 10.1080/17450101.2015.1116884.

P. Adey, Mobility (Abingdon: Routledge, 2010).
} 
the resulting sparse and dense networks produced through our encounters. ${ }^{4}$ Through such mobilities-based academic encounters, I engage Michel Foucault's notion of the heterotopia ${ }^{5}$ to illustrate the role of the university as a knowledge-producing and disseminating project that finds its purpose through the movement and circulation of people, objects and information across time and space and at various scales.

\section{Copresence: A vignette from the Centre for Humanities Research Winter School}

I begin with a vignette involving the copresence of academic bodies at the Centre for Humanities Research (CHR) Winter School at the University of the Western Cape (UWC) in July $2016 .{ }^{6}$ The Winter School gathered scholars from around South Africa and the world to debate the purpose of the university. The meeting took place on the UWC campus but involved multiple and interdependent mobilities ${ }^{7}$ of people, objects, capital and information. The journeys that brought participants together in the meeting room that day involved any number of long- and short-haul flights across continents, car and bus trips across the city, and myriad exchanges of information and capital in the event's fulfilment. As the Winter School programme started, the panel of speakers were seated in front of participants and delegates present in the room as a video camera captured the dialogue in digital form. Digitising our discussion would enable those not able to join us at the event to benefit from the dialogue with their asynchronous virtual presence on the internet - another type of mobility - for many years to come, after the traces of our corporeal mobility had long since disappeared. In spite of the opportunity for the asynchronous sharing of the dialogue, the impact of our copresence in the room on the production and dissemination of knowledge cannot be discounted. The sociological and sociospatial concept of copresence refers to the conditions in which humans interact with one another in a corporeal sense, face to face and body to body. Increasingly discussed through the lens of electronic proximity, however, copresence at the Winter School was defined by our physical proximity which allowed participants to interact through our corporeal copresence.

The purpose of the Winter School was to bring together established and emerging scholars in the humanities for a week of dialogue, debate, sharing and creation of knowledge. A shared outcome of our corporeal copresence at the Winter School and other similar events is the accumulation of 'network capital', a concept introduced by Urry ${ }^{9}$ and used more recently by Storme et al. to characterise 'the different types of sparse and dense networks produced through different forms of "meetingness", and the different roles in the academic labour process. ${ }^{10}$ The accumulation of network capital is contingent upon copresence with other academic bodies sharing knowledge

\footnotetext{
Storme et al., 'Mobility and Professional Networks'.

M. Foucault, 'Of Other Spaces, Heterotopias', Architecture, Mouvement, Continuité, 5 (1984), 46-49, https://foucault.info/doc/ documents/heterotopia/foucault-heterotopia-en-html (accessed 16 October 2017).

S. Zhao, 'Toward a Taxonomy of Copresence', Presence, 12(5) (2003), 445-455.

Sheller and Urry, 'The New Mobilities Paradigm', 212.

Zhao, 'Toward a Taxonomy of Copresence', 445.

J. Urry, 'Small Worlds and the New "Social Physics"', Global Networks, 4(2) (2004), 109-130.

Storme et al., 'Mobility and Professional Networks', 2.
} 
across dispersed networks, both sparse and dense. Being together at the Winter School provided the opportunity to accumulate network capital through the movement of academic bodies as well as bodies of academic knowledge by generating new ideas from old, and by sharing perspectives from a broad array of participants. In our debates over the role of the university, we were taking part in an age-old ritual of the academic project that underpins the purpose of the university.

\section{Mobility in past and present university life}

The movement of scholars has for centuries formed an essential element in the production and dissemination of knowledge and knowledge networks as they pass through and between the ivory towers of the university and the real world beyond. ${ }^{11}$ At the same time, the 'mobilities turn' in the social sciences ${ }^{12}$ and the resulting debates on the deterritorialisation of education from the confines of institutions focus on how a mobilities perspective 'necessitates thinking relationally and contextually about educational processes and the interplay of structure/fixity and agency/flows. ${ }^{13}$ Although initially the exclusive domain of the elite, the twenty-first-century university has been given a new mandate that too may be understood through mobility. In the context of globalisation and the resulting world of seemingly faster and frictionless flows, the twenty-first-century university, according to Brian Denman, has a developmental function. As he notes,

The liberalization of free trade and the shift of emphasis from élite to mass education which followed may have furthered a wave of conviction that knowledge production could provide greater economic security and standards for all and, perhaps in a self-serving way, ensure hopeful prospects of a healthier, more prosperous nation. ${ }^{14}$

Thus, for the university, its purpose may be directly tied to mobility and its need to facilitate the flows embedded in Manuel Castells' notion of the network society. ${ }^{15}$ Yet, within the network society, mobility is a resource that is shared unequally, like so many others. It follows that the access to mobility on the part of university scholars and students will be similarly uneven. As Doreen Massey argues, ${ }^{16}$ power geometry demonstrates how 'different social groups, and different individuals, are placed in very distinct ways in relation to...flows and interconnections. ${ }^{17}$ Such power geometries exist and influence mobility within and across universities in Africa as

11 For an extensive history of the modern university, see Sheldon Rothblatt, The Modern University and Its Discontents: The Fate of Newman's Legacies in Britain and America (Cambridge: Cambridge University Press, 1997).

12 J. Urry, Sociology beyond Societies: Mobilities for the Twenty-First Century (London: Routledge, 2000).

13 J. Waters, 'Education Unbound? Enlivening Debates with a Mobilities Perspective on Learning', Progress in Human Geography, 41(3) (2017), 280 (emphasis added).

14 B. Denman, 'What Is a University in the 21st Century?' Higher Education Management and Policy, 17(2) (2005), 12.

15 M. Castells, The Rise of the Network Society: The Information Age: Economy, Society, and Culture (Oxford: Blackwell, 1996).

16 D. Massey, 'Power-Geometry and a Progressive Sense of Place' in J. Bird, B. Curtis, T. Putnam, G. Robertson and L. Tickner, eds., Mapping the Futures: Local Cultures, Global Change (London: Routledge, 1993), 59-69; D. Massey, 'A Global Sense of Place', Marxism Today, 38 (1991), 24-28.

17

Massey, 'A Global Sense of Place', 25. 
elsewhere. Influenced by thinkers such as Massey, mobility scholars assert that mobility is not a neutral concept, nor is it one that is equally distributed. Rather, mobility itself is contested. The contested nature of mobility arises due to its differential distribution. As Tim Cresswell notes, ' $[\mathrm{m}]$ obility is a resource that is differentially accessed. One person's speed is another person's slowness. Some move in such a way that others get fixed in place. ${ }^{18}$ The scholar who is part of the modern university shares an affinity with vagabonds, ${ }^{19}$ explorers, pilgrims and migrants in their obligation to be mobile. ${ }^{20}$ This genus of homo mobilus is shaped by the traces of their movements, which form the basis of their identity and subjectivity. In the fifteenth century (as in the present), the vagabond was seen as a dangerous mobile subject due to the combination of poverty and mobility. ${ }^{21}$ The unpredictable movements of the vagabond are stigmatised at the same time as they underpin the identity of the vagabond's mobile subjectivity. Similarly, the subject of the university scholar is one that has for centuries relied on movement to gather and disseminate academic knowledge. Given the social, environmental and economic costs of corporeal mobility in the present, ${ }^{22}$ the kinetic scholar is as dangerous and endangered in the midst of austerity as the romanticised vagabond of years gone by. Copresence with academic others involves many challenges at the same time that are necessary for the work of a university to move forward.

\section{The intended purpose of the contemporary university: Relationships at scale}

Moving forward means that the contemporary university by necessity maintains relationships on both local and global scales. Such relationships maintain an oftentenuous balance of local relevance that situates the university in its immediate context while remaining connected to - and in conversation with - other universes on a global scale. The intended purpose of the university in fostering relationships at a variety of scales, and the role of mobility in that pursuit, is evident in the missions of South African institutions of higher education in spite of their varying histories, student and staff profiles, and relationships with local and global contexts. Looking at my own institution, UWC, one of a handful of historically black universities in South Africa, as well as two that emerged as elite whites-only institutions - since transformed - will help to illustrate the role of relationships across these scales. UWC sees itself as

a national university, alert to its African and international context as it strives to be a place of quality, a place to grow. It is committed to excellence in teaching, learning and research, to nurturing the cultural diversity of

18 T. Cresswell, 'Towards a Politics of Mobility', Environment and Planning D: Society and Space, 28(1) (2010), 21.

19 T. Cresswell, 'The Vagrant/Vagabond: The Curious Career of a Mobile Subject' in T. Cresswell and P. Merriman, eds., Geographies of Mobilities: Practices, Spaces, Subjects (Farnham: Ashgate, 2011), 239-253.

20 Storme et al., 'Mobility and Professional Networks'.

21 Cresswell, 'The Vagrant/Vagabond'.

22 J.V. Beaverstock, B. Derudder, J. Faulconbridge and F. Witlox, 'International Business Travel: Some Explorations', Geografiska Annaler: Series B, Human Geography, 91(3) (2009), 193-202. 
South Africa, and to responding in critical and creative ways to the needs of a society in transition. ${ }^{23}$

UWC's mission demonstrates a self-awareness of its position within multiple scales of a network society, from the national to the continental. It is one that demonstrates a commitment to mobility in at least two of the exemplars discussed previously: the copresence of academic bodies in teaching and learning, and the extension of university activities beyond academia in its 'critical and creative' responses to worlds outside academia. At the same time, the mission of UWC recognises the past inequalities and frictions in South African society, lending credence to the power geometry that has shaped our past.

In addition to its focus on teaching and learning, the mission of the University of Cape Town (UCT) highlights the importance of building and maintaining networks across a variety of scales, while also recognising the directionality of flows in the network society of academia. In UCT's case, it is the role of the university in Africa to highlight the uniqueness and elevate the status of African scholarship while sharing it with the world as they

seek to advance the status and distinctiveness of scholarship in Africa through building strategic partnerships across the continent, the global south and the rest of the world. ${ }^{24}$

Like its counterpart UWC, UCT acknowledges its situation in the global South, which, although unspoken, suggests that the situatedness in the region provides unique challenges and opportunities. Similarly, the University of the Witwatersrand's (Wits') mission firmly acknowledges the African soil beneath its feet while it endeavours to 'make a difference', similar to Denman's ${ }^{25}$ view of the twenty-first-century university. Like its counterparts UWC and UCT, Wits fosters relationships at multiple, concentric scales from the continent to the globe as it tries

to discover what lies beneath the Earth's surface to saving lives through better healthcare systems, Wits is on the ground, making a difference. We have over 50 active projects on the African continent and the University is represented globally through our partnerships, collaborations, staff and student exchanges and our alumni around the world. ${ }^{26}$

Ideally, in the cosmopolitan view of the university as seen through the Wits mission, a university will be firmly grounded in its locality, with thick connections to worlds beyond. Mobility is thus critical to the core mission of the university in Africa. However, while movement, circulation and flow may be critical to the concept of

\footnotetext{
See https://www.uwc.ac.za/Pages/Mission.aspx (accessed 7 October 2017).

See https://www.uct.ac.za/about/intro/ (accessed 29 April 2017).

Denman, 'What Is a University in the 21st Century?'

See https://www.wits.ac.za/about-wits/ (accessed 29 April 2017).
} 
mobilities, so too are notions of fixity, stasis and immobility ${ }^{27}$ that emerge through the experience of friction. Friction, in the case of the university and its subjects, may be applied not only through visa regimes and inequalities embedded in the past, but also through disruption and austerity.

\section{The university and mobility}

Since the dawn of the 'mobilities turn', ${ }^{28}$ geographers and other social scientists have sharpened their focus on the role of mobility in shaping everyday social life $\mathrm{e}^{29}$ through the movement and circulation of humans, non-human animals, objects, capital and information, as well as on the distinction between 'movement' as a displacement of location $^{30}$ and mobility which is the embodied experience of socially produced motion that is mediated by power, subjectivity and temporality, amongst others. In spite of the recent focus on the complexities of mobility, much of the research inspired by the mobilities turn has concentrated on transportation hubs, as highlighted by David Bissell, ${ }^{31}$ and less on the knowledge institutions such as universities that serve as hubs for the mobility of knowledge. In my consideration of the purpose of the university in Africa through the lens of mobility, I highlight three examples: corporeal mobility in development and maintenance of academic networks; corporeal mobility in developing new knowledge through fieldwork; and the transfer of knowledge through the mobility of information in the form of access to data, information and academic outputs.

In the first of these forms of mobility, the body of the scholar comes together with other bodies to share and gather new knowledge, as I did with my fellow participants at the CHR Winter School. The same occurs in seminars, conferences and in our everyday teaching in the university setting where we share knowledge with students, build upon existing knowledge that they possess, and create new knowledge through debate and dialogue. When corporeal mobility enables copresence, knowledge is shared and networks are made stronger. New ideas are revealed by a kind of academic serendipity. As Storme et al. note, 'By listening to a presentation or participating in a conversation on an unexplored or unfamiliar topic, one might discover a new idea, technique, research method, etc.'32 - a point illustrated by one of their respondents who compared the experience of conference attendance to listening to a radio instead of an iPod: "Suddenly you hear something that you wouldn't have tuned into if you had compiled your own playlist...So, it broadens your scope and keeps the curiosity". ${ }^{33}$ Thus, to be mobile is to open oneself to new ideas and stimuli. In the dense and kinetic mobile worlds of scholars, the movement and circulation of

\footnotetext{
Cresswell, 'Towards a Politics of Mobility'.

28 Sheller and Urry, 'The New Mobilities Paradigm', 212; M. Sheller, 'From Spatial Turn to Mobilities Turn', Current Sociology, 65(4) (2017), 623-639.

29 T. Cresswell and P. Merriman, eds., Geographies of Mobilities: Practices, Spaces, Subjects (Farnham: Ashgate, 2011).

30 Ibid.

31 D. Bissell, 'Institutionalising Mobilities Research: Networks, Regions, Futures', New Zealand Geographer, 73(2) (2017), 141-144.

32 Storme et al., 'Mobility and Professional Networks', 11.

33 Ibid.
} 
bodies and bodies of knowledge can seem frenetic. But, as Urry notes, they need to come together regularly in 'meetingness', ${ }^{34}$ producing new forms of capital which he calls 'network capital' and 'networked sociality' - experiences that those who might be watching at home through the video footage would unfortunately miss. More telling than that, however, are the mobile inequalities that are evident even within the privileged few in the room. The fact that most of the overseas delegates came from countries as far away as the USA is evidence of both the enormous scale of corporeal mobility in the academic project, but also of the unevenness in its distribution since delegates from the USA (with US passports) do not require visas for entry into South Africa. As Eric Neumayer demonstrates, ${ }^{35}$ the same might not be the case for South Africans wishing to extend their academic networks in the opposite direction. As he states, 'Poorer countries have an incentive to exempt passport holders from highincome countries from visa restrictions in the hope of bolstering foreign investment and knowledge spillovers into their country. ${ }^{36}$ While foreign investment may not be a top priority for scholars, the 'spillover' of knowledge through the copresence of academic bodies certainly is. Neumayer's analysis concludes that a world of seemingly borderless travel is available for passport holders from OECD (Organisation for Economic Cooperation and Development) countries, while much of the rest of the world is bound tightly by visa-restricted international mobility. Thus, obligations of presence are both central to the academic project, and yet challenging for many scholars from African universities.

Obligations of presence do not limit themselves to meetings and 'meetingness', but also to being present by doing research work elsewhere through the study of objects, places or events in fieldwork. ${ }^{37}$ In order to gather new knowledge, it is often necessary to leave the confines of the university itself to perform research in the field, or to otherwise extend the collection of knowledge outside the university through the study of texts, or engagement with other publics as an artist or community activist. Like the previous example, fieldwork involves multiple and intersecting mobilities of the researcher, the object(s) of their study, the movement of capital and information. Fieldwork involves a foray into the messy real world outside of the ivory tower of academia. It provides an opportunity to gather new knowledge and to test theories that are developed within a body of knowledge.

The third example of mobility is the movement and circulation of bodies of knowledge through access to data, information and published academic knowledge. If the university is part of a broader network of universes, and the knowledge produced within those universes is spread across sparse and dispersed networks, then access to particular points of knowledge is critical. These sources include peer-reviewed academic journals, published books, unpublished manuscripts, archives and other sources of data that may otherwise provide important access to new ideas. Access to

34 Urry, 'Small Worlds and the New "Social Physics"', 121.

35 E. Neumayer, 'Unequal Access to Foreign Spaces: How States Use Visa Restrictions to Regulate Mobility in a Globalised World', Transactions of the Institute of British Geographers, 31(1) (2006), 72-84.

36 Ibid., 76

37 Storme et al., 'Mobility and Professional Networks'. 
these sources, while traditionally in print, has increasingly migrated to digital platforms via the internet. The actual and potential movements of data, information and published academic outputs help to organise and structure not only social life ${ }^{38}$ but academic life as well.

The resulting function of the university can be understood through the three examples of mobility highlighted above. All three examples demonstrate the impact of movement, circulation and flows through and across university environments. They also mirror the movement of other elements of social life in that their mobilities are inherently political, and thus contested and unequally distributed. Such inequalities are especially prevalent in the global South, as evidenced from my point of departure in South Africa. If mobility can be understood as a critical element in the purpose of the university, then I turn to consider the relationships that movement and circulation of academic bodies and bodies of academic knowledge afford across a variety of scales.

\section{Frictions, power geometry and disruption}

As demonstrated above in examples of mobility in the university function, frictions are hallmarks of an uneven landscape of knowledge production. In my subjectivity as an academic, I am bound to engage with a broader universe of knowledge in often dispersed and distanced networks. The work that I do is embedded in the mission of my university, similar to its counterparts', while also being bound by the limitations of power geometry. While the work of academics in South Africa has long been governed by unevenness, recent social and political developments in combination with greater access to mobile technologies have compelled academics in South Africa to engage with other scholars and our students in new and novel ways. Trading my corporeal mobility for the virtual kind does not solve the challenges of the disrupted or the austere university, and it may in fact limit who I am and who I can be within the universe of universities.

In late 2015 and 2016, South African higher education experienced disruption in the form of the FeesMustFall movement. At the beginning - and to the present - the student movement focused on achieving the goal of access to quality and affordable higher education for a more just society. As the movement grew in size and scale, protests erupted on campuses across the country. Protestors began by interrupting lectures and tutorials, asking lecturers to cease their teaching, and obliging students to close their books and to make their presence visible by joining the call for a general strike. Protestors marched through campuses, mobilising the movement in a literal sense, taking to the streets in a visual display of solidarity and power. They also used mobility and immobility as a strategy to cut off the flow of people through informal roadblocks within campus roadways and at entrances. The 'mobilisation' of the FeesMustFall movement harnessed mobility as a tactic for ceasing university 
operations, and as a strategy for building awareness and support for the movement. Such mobilisations are not new in South Africa. Rather, they are evidence of a long history of marching to demonstrate solidarity and to highlight power struggles. Peter Adey underscores the use of 'the walk' in this sense, noting that

Mobilities have long been used as a means to both show up inequalities, power struggles and injustices or, elsewhere, to maintain them. The protest 'march' is a classic example of how people moving through streets, roads and cities works to subvert and contest power by the symbolism and significance of their mobility through space. ${ }^{39}$

As the movement grew in scale and intensity, universities around the country, including my own, were disrupted by clashes between protestors and a combination of private security guards and police. Campuses became contested ground, to which parties on either side of the movement sought to claim their stake. The strategic use of mobility in protest is not just symbolic. It may also be used, at it has been in the South African example, to disrupt. Adey reminds us that mobile protestors 'must alter normality in order to achieve their aim. ${ }^{40}$ Indeed, since the start of the FeesMustFall movement, normality has been replaced by crisis planning, securitisation, access control and carefully managed mobility. Localised and national calls for a shut-down brought campus-based lectures and other academic activities to a halt. Students and staff were barred from many campuses, thus making corporeal copresence in teaching and learning impossible. In response, university management made plans to relocate administrative staff to off-campus sites, while most academics continued to work from home, coffee shops or other sites where internet-based virtual mobility through Wi-Fi and portable computers facilitated connection to networks of interaction. The centrality of the university institution as a node of knowledge transfer was interrupted as meetings with students and fellow academics became dispersed around the city. In essence, the footprint of the university spread, and knowledge transfer was deterritorialised from the university campus.

Novel forms of copresence - whether physically or electronically proximate provide new ways to overcome corporeal mobility with the virtual kind. Just as elearning platforms allow me to reach out to my students and continue some form of interaction in the midst of protest, new models of academic networking in the form of teleconferencing are meant to address the fixities that ground many like me to the home campus. The Environmental Humanities Institute (EHI) at the University of California, Santa Barbara, held its first Nearly Carbon Neutral conference in May 2016. Not only did the conference signal a new strategy for engaging with knowledge networks, it also did so in a radical way to address both fiscal and environmental concerns. The EHI even produced a White Paper $^{41}$ on how others could employ this 
model of conference organisation and academic encounter. While the results of the May 2016 conference seem at first promising, the virtual mobilities on which such a model is based do more than simply destabilise a long tradition of academic networking. Such a model requires us to reflexively consider the very nature of what it is to be an academic within a universe of universes, and to seek connection with other bodies and bodies of knowledge within them. Such technologies change our 'world views', as Martin Heidegger might suggest. ${ }^{42}$ What the airplane did, according to Heidegger, in its annihilation of great distances, ${ }^{43}$ the present-day e-conference platform may do to the dissemination of knowledge. The 'gigantic' scale of global travel made possible by aviation in the twentieth century becomes immediately rescaled to the click of an index finger to start the flow of my words on the small screen.

The obligations of my presence at events around the world and around campus dictate the future of my place in this universe and my university. Seen from the perspective of the global South, however, forming and participating in networks that oblige presence - whether embodied or virtual - is fraught with frictions that go unmentioned by Storme et al. ${ }^{44} \mathrm{I}$ am valued by the demands of my publishing output to produce subsidy that is meant to support the range of bodies in the constellation of my university. At the same time, on the local scale, students and lecturers have a decreasing obligation of copresence in the spaces of teaching and learning as we increasingly use mobile- and internet-based technology to deliver content in more efficient but certainly less embodied ways. For those scholars and students with access to appropriate technology and connectivity, e-learning platforms can enable asynchronous sharing of content. I am perhaps nostalgic for an embodied, physically proximate environment of learning with my students. The opportunities for e-learning by virtual mobility come at the same time that our corporeal mobility in the city is hindered by the challenges of distance, failing infrastructure and cost - the final challenge that is a sign of the condition of persistent austerity that defines the lives of many of the students at my institution. However, the loss of corporeal copresence with students and colleagues comes at a price. As Shanyang Zhao notes,

As physical distance between the communicating individuals increases, the number of sensory channels involved in the communication decreases, starting with the loss of the channels of taste, smell, and touch, and followed by hearing and vision. ${ }^{45}$

Thus, when we trade our corporeal mobility for the virtual kind, the ability to fulfil the cosmopolitan role of the university is diminished. Following in the wake of disruption is austerity, another source of friction that may be applied to academic bodies and bodies of academic knowledge.

\footnotetext{
M. Heidegger, The Question Concerning Technology, and Other Essays (New York: Garland Publishing, 1977).

Ibid.

Storme et al., 'Mobility and Professional Networks'

Zhao, 'Toward a Taxonomy of Copresence', 449.
} 


\section{Austerity and binding}

While austerity and disruption have long fixed the bodies of African scholars and their knowledge, the disruption of university activities following both RhodesMustFall and FeesMustFall protests has led to deeper levels of fiscal austerity in South African universities. While not the focus of this paper, the history of both RhodesMustFall and FeesMustFall can be understood through a mobilities perspective: the former through its call for decolonisation of South African universities - colonialism itself being grounded in the flows of commodities, goods and bodies between colonial powers and their outlying territories. The budgetary strain imposed by the disruption of university operations, damage to property and non-payment of fees demonstrates the capacity of austerity to discipline the proximity and scale of our engagements with other universes by limiting the extent to which we can travel, meet, interact, and access and share knowledge with others. Seen through the prism of mobilities, the movement and circulation of capital from student fees, government subsidies, research contracts and other forms of funding became constrained. The flow of capital that powers the engine of the university began to experience friction as students ceased to pay fees, and administrators who typically conduct and channel the flow of university capital inputs and outputs were no longer able to access campus or the instruments of fiscal management.

The diminished flow of capital soon spread to other university functions, and the austere environment quickly metastasised throughout the university system of flows, with impacts on both the movement of academic bodies as well as the bodies of academic knowledge. The drying up of fiscal flows obligated financial managers to curtail spending other than that which was seen as necessary for the basic functioning of the university. Austerity severed the awarding of research grants for university-related travel to academic conferences, thus not only immobilising the academic bodies of scholars, but, by extension, also stymying the transfer of knowledge that might have been facilitated by the scholar's participation. Austerity also retracted budgets meant for fieldwork and field trips for undergraduate and postgraduate students, thus curbing the uptake of new field-based knowledge.

Austerity has also had a direct impact on the movement and circulation of bodies of knowledge through limited access to data, information and published academic knowledge. Situated within a broader network of universes, the university in Africa accesses and transfers knowledge across sparse and dispersed networks by way of peer-reviewed academic journals, published books, unpublished manuscripts, archives and other sources of data that mobilise new ideas. However, the austere university binds the scholar and the student alike through the inability to access material from journals whose subscriptions my university has dropped due to budgetary constraints. The austere university weighs the value of movement against the potential for network capital. It also limits the movement and transfer of knowledge through shrinking access to journal subscriptions, the loss of budget for new library acquisitions or copyright approval for use of existing resources in teaching. As one of my postgraduate students recently informed me during his mid-year progress 
report, 'My research has hit a pay-wall' - meaning that the ability to move forward has been stalled by an encounter with a boundary in the mobility of a body of academic knowledge. The journals that we had access to in the past are no longer available in the present.

If austerity, as John Mowitt noted at the opening of the CHR Winter School, is the burning of the subject, it is then the curtailing of mobility in both corporeal and material senses that sears the subjectivity of the scholar and the student. Thus, austerity both binds (ligare) and burns (sears) the capacity of academic bodies to be present while also restricting their ability to access and accumulate network capital. The impacts of both disruption and austerity may, however, be put to productive use as they shed light on the purpose of the university as an instrument of attraction and dispersal.

\section{Attraction and dispersal: The university as heterotopia}

The university as a space and as an institution of civil society does not exist in a vacuum. Although the roots of such institutions are elitist, in the present day the university has assumed a critical developmental function, as evident in the mission statements of three South African institutions of higher education discussed here. I argue that the university exists, as Foucault would suggest, in the heterogeneous space of the social world:

In other words... [the university does] not live in a kind of void, inside of which we could place individuals and things. We do not live inside a void that could be colored with diverse shades of light, we live inside a set of relations that delineates sites which are irreducible to one another and absolutely not superimposable on one another. ${ }^{46}$

The university is, in Peter Johnson's reading of Foucault, both a macro- and microcosm of society. ${ }^{47}$ The university, like the heterotopia, 'replicates, exaggerates and reduces' other worlds. ${ }^{48}$ Movement and circulation help to enact the relationships that emerge from the university setting. Maintaining relationships within and outside of the university and the transfer of knowledge between these sites is thus at the heart of both the university's intended purpose and resulting function. The university is a site that necessarily can and must connect with a diverse set of others to achieve its aim. Rather than understand the university as a single space with connections, the purpose of the university can thus be understood as a Foucauldian heterotopia ${ }^{49}$ in the sense that the university is capable of juxtaposing multiple sites into the setting of the university campus. Although it has been critiqued as a messy and elusive

\footnotetext{
Foucault, 'Of Other Spaces, Heterotopias'.

P. Johnson, 'The Geographies of Heterotopia', Geography Compass, 7(11) (2013), 790-803.

Ibid., 798.

Foucault, 'Of Other Spaces, Heterotopias'.
} 
concept,$^{50}$ the sociotemporal aspects of the heterotopia speak to the mirroring, distorting and unsettling qualities of the university as a site of knowledge accumulation, formation and transfer.

As understood through the combined prism of the new mobilities paradigm and Foucault's heterotopia, the function of the university is to unite academic bodies and bodies of academic knowledge from sparse and dispersed networks into a space that collides them, reorganises them and catalyses them in the production and dissemination of new knowledge. Foucault characterises the heterotopia as a place

capable of juxtaposing in a single real place several spaces, several sites that are in themselves incompatible. Thus it is that the theater brings onto the rectangle of the stage, one after the other, a whole series of places that are foreign to one another. ${ }^{51}$

Similarly, the university brings together academic bodies and bodies of academic knowledge that are strangers. As a heterotopia, the role of the university as a knowledge-producing and disseminating project finds its purpose through the movement and circulation of people, objects and information across time and space and at various scales. Yet, from the perspective of a scholar within a university in the global South, these movements and circulations are subject to power geometry and frictions that may not be present elsewhere. Heterotopias also exact a disciplining force on those bodies that circulate within and through them. Without mentioning the heterotopia explicitly, Foucault nonetheless highlights the restraining and regulating impact that institutions such as schools, prisons, factories and hospitals have on the subjects within them..$^{52}$ Reflecting on Foucault's concept, Johnson acknowledges the disturbing and unsettling impact of heterotopias wherever they 'shed their light. ${ }^{53}$ Perhaps more pointedly, Johnson's analysis of a range of scholarship on Foucault's heterotopia demonstrates how the spatial idea of the heterotopia

lends itself to those who wish to explore interdisciplinary approaches and spaces; it encourages sites to be used as a starting point for research as both a conceptual method and object; it helps disrupt established thought, practice and human subjectivities; it resists the settling of binary thinking; and it assists in formulating new relationships and alliances. ${ }^{54}$

Such a definition of heterotopia maps precisely on the purpose of the university as a site for knowledge production and dissemination through the movement and circulation of people, objects and information across time and space and at various

\footnotetext{
Johnson, 'The Geographies of Heterotopia'.

Foucault, 'Of Other Spaces, Heterotopias'.

M. Foucault, Discipline and Punish: The Birth of the Prison, translated by Alan Sheridan (London: Allen Lane, 1977).

Johnson, 'The Geographies of Heterotopia', 800.

Ibid.
} 
scales. Seen from a South African university, the heterotopia results in a productive mobilisation of knowledge and bodies in the academic project at the same time as it is rocked with frictions from inside and out. In spite of this, the scholar and the student alike are obligated to be present in these circulations. The importance of movement and circulation within and outside the university is made evident in the midst of disruption and austerity, where the binding and burning of academic subjects reveals the purpose of the university itself. 